\title{
Why Do Firms Invest in Consumer Advertising with Limited Sales Response? A Shareholder Perspective
}

Marketing managers increasingly recognize the need to measure and communicate the impact of their actions on shareholder returns. This study focuses on the shareholder value effects of pharmaceutical direct-to-consumer advertising (DTCA) and direct-to-physician (DTP) marketing efforts. Although DTCA has moderate effects on brand sales and market share, companies invest vast amounts of money in it. Relying on Kalman filtering, the authors develop a methodology to assess the effects from DTCA and DTP on three components of shareholder value: stock return, systematic risk, and idiosyncratic risk. Investors value DTCA positively because it leads to higher stock returns and lower systematic risk. Furthermore, DTCA increases idiosyncratic risk, which does not affect investors who maintain well-diversified portfolios. In contrast, DTP marketing has modest positive effects on stock returns and idiosyncratic risk. The outcomes indicate that evaluations of marketing expenditures should include a consideration of the effects of marketing on multiple stakeholders, not just the sales effects on consumers.

Keywords: stock price returns, stock price volatility, pharmaceutical marketing, advertising, time-varying parameters, Kalman filtering

$\mathbf{S}$ tock prices reflect the expected future value of firms. This value also depends on marketing expenditures, both through intermediate metrics and in the form of a direct effect on investors (Srinivasan and Hanssens 2009). Such effects are evident in the levels of (first moment) and fluctuations in (second moment) stock prices. Thus, in principle, marketing expenditures such as advertising may have limited sales response effects but significant investor response effects, or vice versa.

Recent research has demonstrated that a firm's advertising affects stock returns, beyond the effect of advertising on revenues and profits (e.g., Joshi and Hanssens 2010). Simi-

Ernst C. Osinga is Assistant Professor of Marketing, CentER, Department of Marketing, Tilburg University (e-mail: e.c.osinga@uvt.nl). Peter S.H. Leeflang is Frank M. Bass Professor of Marketing, Department of Marketing, Faculty of Economics and Business, University of Groningen (e-mail: p.s.h.leeflang@rug.nl), and BAT Professor of Marketing, LUISS Guido Carli University, Rome. Shuba Srinivasan is Associate Professor of Marketing and Dean's Research Fellow, Boston University (e-mail: ssrini@bu. edu). Jaap E. Wieringa is Associate Professor of Marketing, University of Groningen (e-mail: j.e.wieringa@rug.nl). This research was conducted as part of the first author's doctoral thesis. The authors thank the Marketing Science Institute for financial support. For their insightful comments, the authors thank the two anonymous $J M$ reviewers and participants at the 2007 and 2008 Marketing Science Conferences, the research seminar of the School of Management at Boston University, the 2008 Stakeholder Marketing Conference in Boston, and the Marketing Strategy Meets Wall Street Conference at Emory University in 2009. They also thank Dominique Hanssens and C.B. Bhattacharya for their insightful comments. Raj Srivastava served as guest editor for this article. larly, communicating the added value created by product innovation yields greater firm value effects (e.g., Srinivasan et al. 2009). As McAlister, Srinivasan, and Kim (2007) report, a firm's advertising also lowers its systematic market risk. Consequently, to evaluate marketing expenditures properly and improve marketing resource allocations, models that consider the effects of marketing expenditures on multiple stakeholders, such as customers and investors, are necessary (e.g., Luo 2007).

In this study, we examine the influence of advertising expenditures on investors and thus (1) the levels of stock returns and the risk associated with these returns, distinguishing (2) systematic (market risk factor) and (3) idiosyncratic (firm-specific) risks. Our framework also moves beyond the theories and variables used in previous studies to determine whether firms should invest in marketing actions with limited sales response. In doing so, this study offers new contributions over previous research (e.g., Joshi and Hanssens 2010; McAlister, Srinivasan, and Kim 2007). In particular, we simultaneously estimate the effects of marketing on all three components of shareholder value using Kalman filtering. Building on the four-factor model that Carhart (1997) proposes, we develop a dynamic model to relate pharmaceutical direct-to-consumer advertising (DTCA) and direct-to-physician (DTP) marketing expenditures to stock returns and volatilities while controlling for financial performance.

Pharmaceutical DTCA is a relatively new, and heavily debated, phenomenon: The Food and Drug Administration (FDA) relaxed regulations on DTCA only in 1997. Recent 
research suggests limited short- and long-term effects of DTCA on sales, which places pharmaceutical marketers, similar to their counterparts in other industries, under constant pressure to justify their sales and marketing budgets. We investigate why many pharmaceutical firms continue to spend on DTCA despite the limited sales effects. Prior research in this field has largely focused on marketing performance outcomes, such as sales, share, and compliance (Kremer et al. 2008; Manchanda et al. 2005; Wosinska 2005), which cannot explicitly quantify the financial outcomes of pharmaceutical DTCA. We are not aware of any study that systematically quantifies the impact of DTCA on stock returns and volatilities. To fill this gap, we aim to capture the impact of DTCA on returns and volatilities and compare the effects of DTCA with those of other marketing expenditures, such as those directed toward physicians.

The outcomes of our study reveal that investors' response to DTCA is positive. On average, over time, and across firms, we find that DTCA leads to higher stock returns and lower systematic risk. The effect of DTCA on idiosyncratic risk is positive. In contrast, DTP marketing has only modest positive effects on stock returns and idiosyncratic risk. This has important consequences for the allocation of marketing expenditures over DTCA and DTP.

In the next section, we provide some background on DTCA in the pharmaceutical industry, followed by a conceptual framework of the relationship between marketing expenditures and shareholder value. After we describe our research methodology, we provide a description of the marketing and financial data used, and then we outline the empirical results. Finally, we offer managerial implications, formulate conclusions, and discuss their implications for marketing academics and practitioners.

\section{Background on Pharmaceutical DTCA}

Before 1980, pharmaceutical DTCA was nearly nonexistent. Beginning in the 1980s and early 1990s, a limited amount of DTCA began appearing. Expenditures on DTCA increased dramatically after the FDA relaxed its regulation of ethical drug advertising on television in August 1997. For the first time, the FDA permitted product-specific DTCA that could mention both the drug's name and the condition for which it was to be used, without disclosing a summary of contraindications, side effects, or effectiveness (a "brief summary") (Rosenthal et al. 2002). Since then, DTCA expenditures have increased faster than expenditures on other marketing instruments in the pharmaceutical industry (IMS Health 2009).

Empirical research establishes only moderate short- and long-term sales effects from DTCA (e.g., Berndt et al. 1995; Kremer et al. 2008; Narayanan, Desiraju, and Chintagunta 2009; Osinga, Leeflang, and Wieringa 2010; Wittink 2002). According to Kremer and colleagues (2008), DTCA elasticities vary across therapeutic classes, with an average of .073. Other pharmaceutical research establishes that DTCA has limited to no effect on the prescribing behavior of physicians (Law, Majumdar, and Soumerai 2008). Iizuka and Jin (2005) and Wosinska (2005) find that DTCA does not affect drug brand choice. Amaldoss and He (2009) and Stremersch and Van Dyck (2009) summarize other salient empirical findings on DTCA. Medical researchers also find insignificant effects on patient requests for prescription medication (Parnes et al. 2009). In contrast, there are many empirical studies in which significant effects of DTP have been found. In their meta-analysis, Kremer and colleagues (2008) find average elasticities of detailing efforts of .326 and of DTP advertising of .123 over all therapeutic classes that have been studied thus far.

A plausible explanation for the moderate DTCA effect on sales is a prisoner's-dilemma situation; that is, firms' DTCA efforts cancel each other out, and if a firm were to cease its DTCA activities, it would lose significant sales. ${ }^{1}$ However, two empirical realities run counter to this hypothesis. First, manufacturers with drugs in the same category often do not allocate their DTCA budgets over time in the same way. Therefore, although DTCA effects may potentially be offset by competitive DTCA in the next period, a sales model would show significant own and cross-effects. Second, drugs are generally protected by patents. As a consequence, a pure competitor frequently does not exist, and in some categories, a drug may even have no competition at all. Wittink (2002) and Osinga, Leeflang, and Wieringa (2010) study a large number of categories with differing levels of competition and conclude that, in general, DTCA has only a modest sales impact. If DTCA activities are successful but canceled out by competition, categories with little or no competition would show significant sales effects. As far as we are aware, no such evidence has been obtained, leaving unresolved the question of why firms invest in consumer advertising with limited sales response.

In summary, do these various findings from different research fields mean that DTCA is not effective and that the pharmaceutical marketing budget is not optimally allocated? We take a broader view of DTCA and consider the effects of DTCA on shareholder value to answer that question.

\section{Research Framework: Marketing Expenditures and Shareholder Value}

Shareholder value depends on stock returns and risk. Stock returns are the percentage change in a firm's stock price; we define risk according to two components: systematic and idiosyncratic risk (Bansal and Clelland 2004; Campbell et al. 2001). Systematic risk entails the economywide sources that affect the overall stock market (e.g., interest rate shifts, exchange rates, macroeconomic developments) that cannot be diversified away through a balanced portfolio. Thus, investors can use the sensitivity of an individual stock's return to systematic (market) risk to determine the stock price. Idiosyncratic risk is the uncertainty about the price of a specific stock - that is, volatility not associated with that of other stocks. This type of risk can be eliminated through effective portfolios, and it does not influence investor valuation of the stock (Brealy, Myers, and Marcus 2001).

${ }^{1}$ We thank an anonymous reviewer for indicating this possibility. 
The efficient market hypothesis implies that stock prices reflect all known information about the firm's future earnings prospects (Fama 1970). For example, investors may expect the firm to maintain its usual level of advertising and price promotions. Developments (in the form of unexpected changes) that positively affect future cash flows result in increases in stock price, while those that negatively affect cash flows result in decreases. Fehle, Tsyplakov, and Zdorovtsov (2005), Frieder and Subrahmanyam (2005), and Grullon, Kanatas, and Weston (2004) show that advertising increases the firm's salience for individual investors, who typically prefer holding stocks that are well known or familiar to them, thus increasing demand for the firm's stock. Accordingly, both unexpected changes in advertising and the total amount of advertising can affect shareholder value.

Several studies assess the effects of marketing actions, including advertising and promotions, on shareholder value. First, a stream of research establishes a relationship between shareholder value and intermediate marketing asset metrics, such as customer equity (Rust, Lemon, and Zeithaml 2004) and brand equity (Madden, Fehle, and Fournier 2006).

A second stream of research measures the direct effects of marketing actions on stock price metrics, which represent the focus of our study. Table 1 summarizes some representative studies of the effect of marketing actions on shareholder value. For example, previous investigations have considered the effects of new products and sales promotions (Pauwels et al. 2004) and the influence of advertising and research and development (R\&D) on the stock returns of firms in the personal computer manufacturing industry (Joshi and Hanssens 2010). McAlister, Srinivasan, and Kim (2007) and Fornell and colleagues (2006) address the omission of risk as an outcome variable in marketing literature by focusing solely on systematic risk. In addition to studying the impact of advertising and, for example, detailing on the levels of returns, we study their effect on systematic and idiosyncratic risk components. Our conceptual framework in Figure 1 illustrates how our study contributes to existing literature in this research stream.

\section{Marketing Expenditures and Levels of Stock Returns}

Advertising can increase shareholder value by increasing revenues. The outcomes of several studies suggest that advertising has a direct effect on firm performance metrics, including sales (Vakratsas and Ambler 1999) and profits (Erickson and Jacobson 1992). Thus, unanticipated changes in the level of advertising affect cash flow expectations. In addition, studies confirm that advertising expenditures create an intangible asset (Barth et al. 1998; Rao, Agarwal, and Dahlhoff 2004). From an investor's perspective, advertising spending has a positive and long-term impact on a firm's market capitalization (Joshi and Hanssens 2010) that persists beyond the indirect effect of advertising through revenues and profits on market capitalization. Furthermore, advertising increases demand for a firm's stock because it enhances the firm's salience for individual investors (Barber and Odean 2008; Fehle, Tsyplakov, and Zdorovtsov 2005; Frieder and Subrahmanyam 2005; Grullon, Kanatas, and
Weston 2004; Lou 2009). Using data from many firms, Chemmanur and Yan (2009) find that stock returns increase in a year of high advertising expenditures but may decline in a subsequent year as a result of advertising wear-out. This effect is likely to be even stronger in the case of pharmaceutical firms, given that advertising expenditures grew rapidly after the regulation relaxation, enhancing the visibility of and attention for pharmaceutical firms. The effect on demand for the firms' stocks likely disappeared in the long run as a result of advertising wear-out and saturated demand; in other words, individual investors will not keep on buying additional units of stock. In summary, we expect that unanticipated increases in DTCA raise stock returns in the pharmaceutical industry. In addition, we expect that this effect is strongest directly following the regulation relaxation. Thus, we posit the following:

\section{$\mathrm{H}_{1}$ : DTCA increases stock returns. \\ $\mathrm{H}_{2}$ : The effect of DTCA on stock returns is strongest directly after the regulation relaxation.}

Unexpected changes in DTP expenditures may alter cash flow expectations. However, the firm's stock price will only be affected when investors observe these unexpected changes. As DTP efforts are directed toward prescribers, investors only observe DTP expenditures through press releases or quarterly or annual reports or by buying these data from a company such as IMS. Inspection of quarterly reports shows that detailed DTP expenditures are typically not provided. Experts in the field and IMS contacts indicate that large investors indeed buy data; however, this mostly involves financial data about companies' or products' market positions. Therefore, we conclude that, in general, investors do not observe DTP expenditures on a weekly or monthly basis. Given the low visibility of changes in DTP spending, we hypothesize the following:

\section{$\mathrm{H}_{3}$ : DTP marketing has no effect on stock returns.}

\section{Marketing Expenditures and Systematic Risk}

Srivastava, Shervani, and Fahey (1998) indicate that the differentiation of a brand through advertising may lead to monopolistic power, which can be leveraged to extract superior product-market performance, perhaps leading to more stable (i.e., less dependent on market performance) earnings in the future. Furthermore, advertising enhances market penetration, makes it easier to launch product extensions, and increases customer loyalty. Through these mechanisms, advertising reduces cash flow volatility (Fischer, Shin, and Hanssens 2009) and, thus, systematic risk. Advertising also may help smooth out the variability in highly seasonal demand patterns, which should lower cash flow volatility. Research findings indicate that advertising and R\&D indeed lower a firm's systematic risk (McAlister, Srinivasan, and Kim 2007).

Advertising also can influence investor portfolio choices. Individual investors, unlike institutional ones, prefer holding stocks of well-known firms (Frieder and Subrahmanyam 2005). Through advertising, firms can enhance awareness among investors and inform them about new products. Thus, firms that engage in higher levels of adver- 


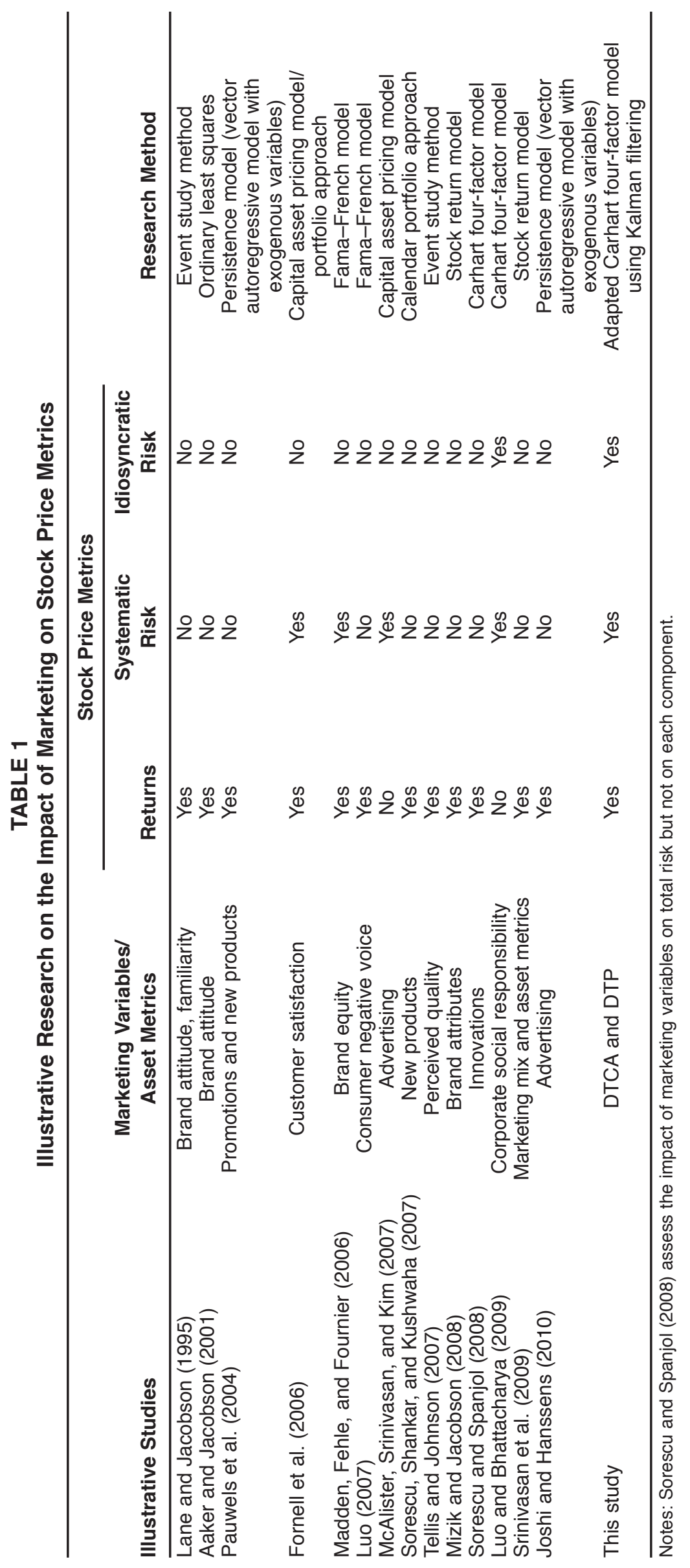


FIGURE 1

Research Framework

Firm Marketing Actions

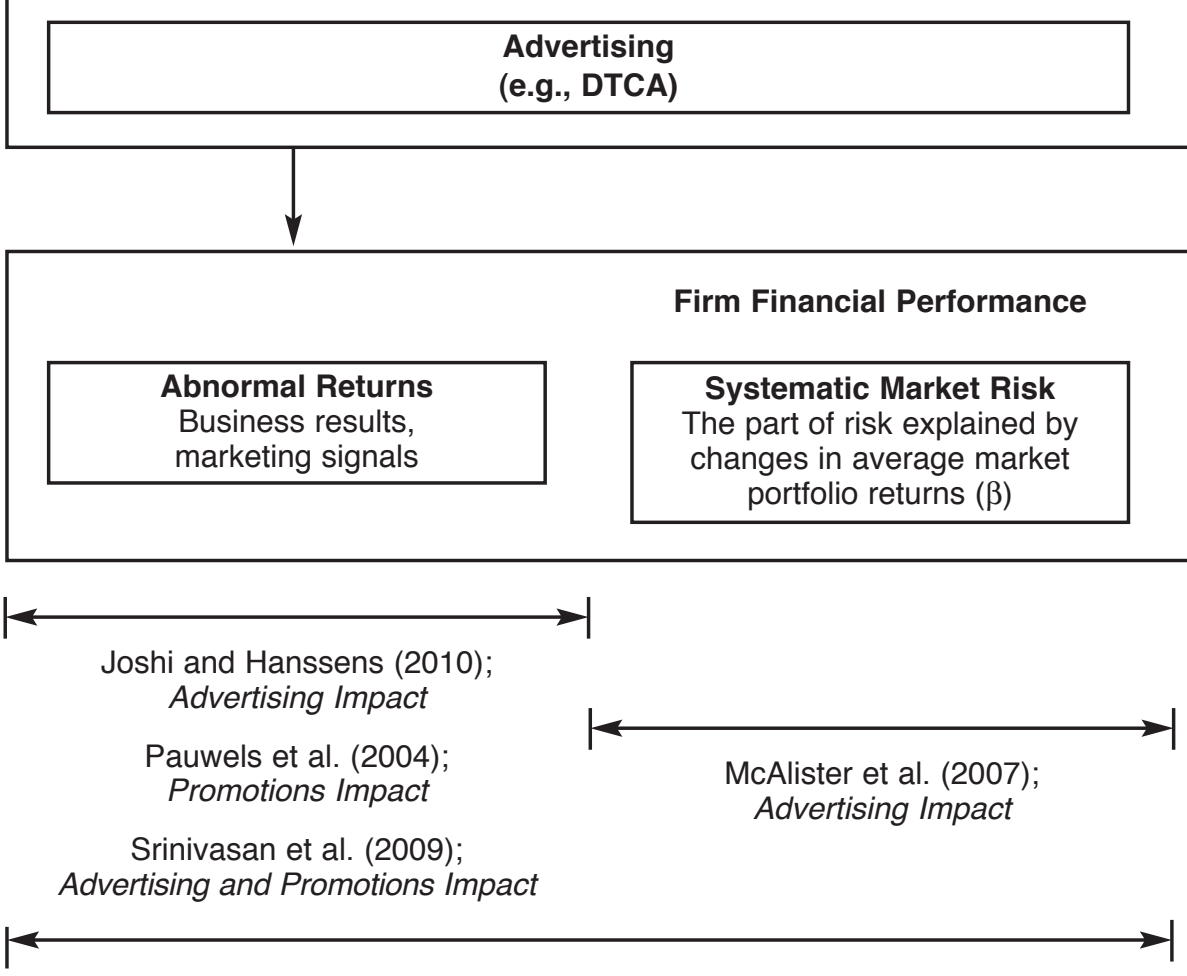

Fornell et al. (2006); Customer Satisfaction Impact

This Study; Advertising and Promotions Impact on Returns, Systematic Risk and Idiosyncratic Risk

tising may have a relatively large number of individual stockholders whose buy and sell decisions would be less coordinated (Xu and Malkiel 2003). This scenario could reduce systematic risk. Indeed, executives value individual investors for their stability and long-term investment objectives (Vogelheim et al. 2001).

Overall, we suggest that the collective benefits of advertising insulate a firm's stock from market downturns and thus lower its systematic risk (Veliyath and Ferris 1997). Because stockholders typically do not have detailed DTP expenditures information, we do not expect any changes in systematic risk due to changes in DTP. Therefore, we propose the following:

$\mathrm{H}_{4}$ : DTCA lowers systematic risk.

$\mathrm{H}_{5}$ : DTP marketing has no effect on systematic risk.

\section{Marketing Expenditures and Idiosyncratic Risk}

Although DTCA may have a favorable effect on two components of firm value - returns and systematic risk-it does not necessarily favor all components. Specifically, critics argue that DTCA provides "incomplete and biased information, leads to inappropriate prescribing, increases costs as a result of the added costs of advertising, and consumes time in the physician-patient encounter" (Parnes et al. 2009, p. 2 ). The effects of DTCA might be negative because the advertisements are legally required to mention the negative side effects of the advertised drug (Wosinska 2005). As a relatively new phenomenon in the context of pharmaceuticals, with potentially mixed effects, it may be difficult for investors to judge the sales effects of DTCA. Furthermore, the lack of substantial sales response effects of DTCA may cause an increase in firm-specific risk. Because DTCA serves as an informational mechanism for individual investors about such things as new product launches, it should enhance, or reactivate, investor awareness. This may cause individual investors to pay more attention to firm-specific news, such as clinical concerns, which would result in a stronger investor response to company news about stock returns-that is, an increase in idiosyncratic risk. This effect is different from the one described for systematic risk, for which we hypothesize that the firm's increased salience among individual investors enhances their propensity to buy the firm's stock, leading to a larger degree of individual investor ownership, which in turn should reduce systematic risk. In the case of idiosyncratic risk, we argue that existing stockholders' awareness may be enhanced, or reactivated, thereby leading to a greater impact of company- 
specific news. Moreover, DTCA may increase risk because the advertisements are required to mention the side effects. It must be noted that the two hypothesized effects do not contradict each other: The stock price may move up or down with the market and, on top of that, display larger fluctuations because of the firm-specific news. We do not expect changes in idiosyncratic risk as a result of changes to DTP, because investors do not directly observe DTP expenditures and DTP marketing has long been in use as a proven communication vehicle in the pharmaceutical industry. Therefore, we hypothesize the following:

$\mathrm{H}_{6}$ : DTCA increases idiosyncratic risk.

$\mathrm{H}_{7}$ : DTP marketing has no effect on idiosyncratic risk.

\section{Research Design and Methodology}

\section{Model Specification}

To assess the impact of marketing expenditures on returns and systematic and idiosyncratic risk, we develop a dynamic model that we estimate using Kalman filtering. As a starting point, we use Carhart's (1997) four-factor model, which Luo and Bhattacharya (2009), Sood and Tellis (2009), and Sorescu, Shankar, and Kushwaha (2007), among others, have applied to a marketing context. The model extends the well-known capital asset pricing model (CAPM) and explains a firm's return premium, which is the difference between the firm's return $\mathrm{R}$ and the return on a risk-free investment $R_{r f}$, according to (1) the excess market return, $R_{m}-R_{r f}$, where $R_{m}$ is the market return; (2) the difference between the return on a portfolio of small firms and that of large firms (small minus big, SMB); (3) the difference between the return on portfolios of high versus low book-to-market equity firms (high minus low, HML); and (4) a momentum factor, defined as the difference in the return between portfolios of firms with high versus low prior returns (up minus down, UMD). Carhart (1997) shows that this four-factor model captures known anomalies in excess returns. For firm i at time t, the four-factor model is as follows:

$$
\begin{gathered}
\left(\mathrm{R}_{\mathrm{it}}-\mathrm{R}_{\mathrm{rft}}\right)=\beta_{0 \mathrm{i}}+\beta_{1 \mathrm{i}}\left(\mathrm{R}_{\mathrm{mt}}-\mathrm{R}_{\mathrm{rft}}\right)+\beta_{2 \mathrm{i}} \mathrm{SMB}_{\mathrm{t}} \\
+\beta_{3 \mathrm{i}} \mathrm{HML}_{\mathrm{t}}+\beta_{4 \mathrm{i}} \mathrm{UMD}_{\mathrm{t}}+\varepsilon_{\mathrm{it}},
\end{gathered}
$$

where $\varepsilon_{\mathrm{it}} \sim \mathrm{N}\left(0, \sigma_{\varepsilon_{\mathrm{i}}}^{2}\right)$. The parameter $\beta_{0 \mathrm{i}}$ captures structural excess returns that should not be present and should be equal to 0 in the case of an efficient market. Short-term excess returns appear in $\varepsilon_{\mathrm{it}}$. The parameter $\beta_{1 \mathrm{i}}$ measures the firm's systematic risk, and $\sigma_{\varepsilon_{\mathrm{i}}}^{2}$ is a measure of idiosyncratic risk (Luo and Bhattacharya 2009). The parameter $\beta_{2 i}$ indicates the extent to which the firm's stock returns move with those from a portfolio of small stocks (higher value for $\beta_{2 \mathrm{i}}$ ) or those from large stocks (lower value for $\beta_{2 \mathrm{i}}$ ); similarly, $\beta_{3 i}$ takes on a higher value when the stock returns show more correspondence with those from high book-to-market equity firms and lower values when they are closer to the returns from low book-to-market equity firms. Finally, $\beta_{4 \mathrm{i}}$ indicates the extent to which the stock returns correspond to those from firms that performed well in the previous period; therefore, when a firm's stock has momentum, we expect a positive, significant estimate for $\beta_{4 \mathrm{i}}$.

Marketing expenditures and levels of stock returns. To test our hypotheses regarding the effects of DTCA and DTP expenditures on stock returns, we extend Equation 1 to include measures of DTCA and DTP. In addition, we include revenues (REV), profits (PROFIT), and R\&D expenditures (RD). These additions help distinguish between direct effects from marketing expenditures and indirect effects that run through these other variables (Joshi and Hanssens 2010; Srinivasan et al. 2009). We do not include competitive variables, because not only pharmaceutical manufacturers compete for investors' dollars. Following Aaker and Jacobson (1994, 2001) and Srinivasan and colleagues (2009), we assume that shareholders only respond when new and unexpected information becomes available (Fama 1970). We do not observe these data but define unanticipated changes $(\mathrm{U})$ through first-order autoregressive models as described in detail in the "Data" section. However, in the case of DTCA, we make an exception: Because shareholders observe DTCA not only in the firms' profit-and-loss statements but also as consumers, we include this variable in both unexpected shocks and levels, operationalized through a stock variable DTCAS, to capture another important difference in the possible effects of DTCA and DTP. Specifically, the timing of information release to investors is continuous and repetitive in the case of DTCA but discrete for DTP. To test $\mathrm{H}_{2}$, we include a dummy variable multiplied by DTCA levels because these, and not the unexpected changes, are likely to drive the firm's salience for individual investors.

Marketing expenditures and systematic and idiosyncratic risk. To test our hypotheses regarding the relationship between DTCA and DTP and the two types of risk, we specify how dynamic risk measures evolve over time and how the marketing expenditures influence these movements. Ghysels (1998) argues that systematic risk changes slowly over time and that an overly volatile measure might lead to worse predictions than a model with a static effect. Building on well-accepted financial models, Braun, Nelson, and Sunier (1995) model systematic and idiosyncratic risk with first-order autoregressive processes and obtain carryover parameters that tend to be close to unity, indicating that the risk components follow a smooth pattern over time. Similarly, using a nonparametric approach, Cai (2007) demonstrates that the pattern of systematic risk over time is smooth. A further indication of the general lack of volatility in the risk parameters is the frequency with which the CAPM and four-factor model are estimated over long data windows. For example, Carhart (1997) uses 30 years of data with differing portfolios, and McAlister, Srinivasan, and Kim (2007) use 5-year windows of firm-level data to estimate CAPMs.

Following Braun, Nelson, and Sunier (1995), we base our specifications for systematic and idiosyncratic risk on autoregressive processes. We incorporate unexpected 
changes in DTCA and DTP, as well as revenues, profits, and R\&D expenditures, as exogenous variables in these specifications. We also include the DTCA stock variable, as we did for the levels of returns. In the case of idiosyncratic risk, we do not add an error term to the equation, which would make the estimation rather more difficult. ${ }^{2}$ Instead, our specification of idiosyncratic risk is a deterministic version of the stochastic volatility model, which has a strong theoretical foundation in finance literature (Durbin and Koopman 2001). This model consists of a series with mean 0 , the exponent of which we multiply by a scaling parameter $\kappa$.

To fine-tune the optimal size of the carryover parameters and the order of the autoregressive processes, we test three alternative specifications: (1) a first-order autoregressive process, (2) a second-order autoregressive process, and (3) a random walk specification, with carryover parameters equal to 1 . The estimation of our full model using the firstand second-order autoregressive models indicates that the carryover parameters only just lie within the unit circle, similar to the results Braun, Nelson, and Sunier (1995) provide. Therefore, it is no surprise that the more parsimonious random walk specification fits even better, as indicated by the Bayesian and corrected Akaike information criteria (BIC and $\mathrm{AIC}_{\mathrm{c}}$, respectively). Therefore, we proceed with the parsimonious random walk specification.

Pooling. Because of the many parameters in our model and the modest number of observations available per firm, we cannot estimate the model at the individual firm level. Instead, we partially pool monthly data from different firms in our sample, similar to Joshi and Hanssens (2010), who pool quarterly data in their analysis. To accommodate firmlevel heterogeneity, we include firm-specific intercepts, systematic risk, and idiosyncratic risk measures. Because we study firms in the same industry, it is likely that there are factors that affect all firms in the same direction, though not necessarily to the same extent. ${ }^{3}$ Examples of such factors include new legislation, epidemics, and new technology available to all firms. Therefore, we specify a full covariance matrix, allowing the errors of the different firms to be contemporaneously correlated. 4

Our final model consists of three parts (Equations $2 \mathrm{a}-2 \mathrm{~d})$. For firm $\mathrm{i}=1, \ldots, 8$, at time $\mathrm{t}$, we have the following.

\section{Levels of Returns}

$$
\begin{aligned}
\left(\mathrm{R}_{\mathrm{it}}-\mathrm{R}_{\mathrm{rf}, \mathrm{t}}\right) & =\beta_{0 \mathrm{i}}+\beta_{1 \mathrm{it}}\left(\mathrm{R}_{\mathrm{mt}}-\mathrm{R}_{\mathrm{rf}, \mathrm{t}}\right)+\beta_{2} \mathrm{SMB}_{\mathrm{t}}+\beta_{3} \mathrm{HML}_{\mathrm{t}} \\
& +\beta_{4} \mathrm{UMD}_{\mathrm{t}}+\gamma_{1} \mathrm{DTCAS}_{\mathrm{it}}\left(1-\mathrm{D}_{\mathrm{t}}\right)+\gamma_{2} \mathrm{DTCAS}_{\mathrm{it}} \mathrm{D}_{\mathrm{t}} \\
& +\gamma_{3}(\mathrm{U}) \mathrm{DTCA}_{\mathrm{it}}+\gamma_{4}(\mathrm{U}) \mathrm{DTP}_{\mathrm{it}}+\gamma_{5}(\mathrm{U}) \mathrm{REV}_{\mathrm{it}} \\
& +\gamma_{6}(\mathrm{U}) \mathrm{PROFIT}_{\mathrm{it}}+\gamma_{7}(\mathrm{U}) \mathrm{RD}_{\mathrm{it}}+\varepsilon_{\mathrm{it}},
\end{aligned}
$$

\footnotetext{
${ }^{2}$ Because our results indicate a small variance for the error term related to systematic risk, we do not regard this omission as a major limitation of our model.

${ }^{3}$ We thank an anonymous reviewer for suggesting this.

${ }^{4}$ Allowing for correlated errors in the equation for systematic risk, $\eta_{\mathrm{it}}$, does not improve model fit.
}

where $\varepsilon_{\text {it }} \sim \mathrm{N}\left(0, \sigma_{\varepsilon_{\mathrm{it}}}^{2}\right)$ such that the correlation between $\varepsilon_{\mathrm{it}}$ and $\varepsilon_{\mathrm{j}}, \mathrm{j} \neq \mathrm{i}$ is equal to $\rho_{\mathrm{ij}}$ and where $\mathrm{D}_{\mathrm{t}}$ is a dummy variable that takes the value 1 in the periods directly following the regulation relaxation and 0 otherwise.

Systematic Risk

(2b)

$$
\begin{aligned}
& \beta_{1 \mathrm{it}}=\beta_{1 \mathrm{it}-1}+\varphi_{1} \mathrm{DTCAS}_{\mathrm{it}}+\varphi_{2}(\mathrm{U}) \mathrm{DTCA}_{\mathrm{it}}+\varphi_{3}\left(\mathrm{U} \mathrm{DTP}_{\mathrm{it}}\right. \\
& +\varphi_{4}(\mathrm{U}) \mathrm{REV}_{\mathrm{it}}+\varphi_{5}(\mathrm{U}) \mathrm{PROFIT}_{\mathrm{it}}+\varphi_{6}(\mathrm{U}) \mathrm{RD}_{\mathrm{it}}+\eta_{\mathrm{it}}
\end{aligned}
$$

where $\eta_{\text {it }} \sim \mathrm{N}\left(0, \sigma_{\eta}^{2}\right)$.

Idiosyncratic Risk

$$
\sigma_{\varepsilon_{\mathrm{it}}}^{2}=\kappa_{\mathrm{i}} \exp \left(\mathrm{h}_{\mathrm{it}}\right)
$$

where $\kappa_{\mathrm{i}}$ is the firm-specific scaling parameter, and

$$
\begin{aligned}
\mathrm{h}_{\mathrm{it}}= & \mathrm{h}_{\mathrm{it}-1}+\lambda_{1} \text { DTCAS }_{\mathrm{it}}+\lambda_{2}(\mathrm{U}) \mathrm{DTCA}_{\mathrm{it}}+\lambda_{3}(\mathrm{U}) \mathrm{DTP}_{\mathrm{it}} \\
& +\lambda_{4}(\mathrm{U}) \mathrm{REV}_{\mathrm{it}}+\lambda_{5}(\mathrm{U}) \mathrm{PROFIT}_{\mathrm{it}}+\lambda_{6}\left(\mathrm{U} \mathrm{RD}_{\mathrm{it}} .\right.
\end{aligned}
$$

In Equations $2 \mathrm{a}-2 \mathrm{~d}$, the $\beta$ parameters correspond to the fourfactor model from Equation 1, and we note that $\beta_{1 \text { it }}$ and $\sigma_{\varepsilon_{i t}}^{2}$ include subscript $\mathrm{t}$ to allow for time-varying systematic and idiosyncratic risk. The $\gamma$ parameters indicate the effects of the marketing, $\mathrm{R} \& \mathrm{D}$, and firm performance variables on returns. The effects of these variables on systematic and idiosyncratic risk are given by the $\varphi$ and $\lambda$ parameter sets, respectively. Firm-specific effects are accommodated through the firm-specific intercepts $\beta_{0 \mathrm{i}}$, the firm-specific error variance scaling parameters $\kappa_{i}$, and the initial values of the systematic risk series $\beta_{1 \mathrm{i} 0}$.

\section{Model Estimation}

We estimate our model with Kalman filtering, as has been applied previously in marketing contexts by, among others, Naik, Mantrala, and Sawyer (1998), Naik and Raman (2003), and Osinga, Leeflang, and Wieringa (2010) in their efforts to model advertising and promotion effects over time and by Xie and colleagues (1997) and Van Everdingen, Aghina, and Fok (2005) to model diffusion processes using an augmented version with continuous states. For example, Van Heerde, Mela, and Manchanda's (2004) and Ataman, Mela, and Van Heerde's (2008) applications of the Bayesian dynamic linear model are related closely to the Kalman filter methodology as well. Our model is linear and Gaussian, so we apply classical Kalman filtering, which is substantially faster than the Bayesian approach.

To apply this method, we first write our model in statespace form and specify it in terms of observation and transition equations. The transition equations describe how the time-varying parameters evolve over time and link to the endogenous variable using the observation equations (Durbin and Koopman 2001; Naik, Mantrala, and Sawyer 1998). We can rewrite Equations $2 \mathrm{a}-2 \mathrm{~d}$ in state-space form using the observation equations 
(3a)

$$
\begin{aligned}
& {\left[\begin{array}{c}
\left(\mathrm{R}_{1 \mathrm{t}}-\mathrm{R}_{\mathrm{rf,t}}\right) \\
\left(\mathrm{R}_{2 \mathrm{t}}-\mathrm{R}_{\mathrm{rf}, \mathrm{t}}\right) \\
\vdots \\
\left(\mathrm{R}_{8 \mathrm{t}}-\mathrm{R}_{\mathrm{rf}, \mathrm{t}}\right)
\end{array}\right]} \\
& =\left[\begin{array}{cccc}
\left(\mathrm{R}_{\mathrm{mt}}-\mathrm{R}_{\mathrm{rf}, \mathrm{t}}\right) & 0 & \cdots & 0 \\
0 & \left(\mathrm{R}_{\mathrm{mt}}-\mathrm{R}_{\mathrm{rf}, \mathrm{t}}\right) & & 0 \\
\vdots & & \ddots & \\
0 & \cdots & 0 & \left(\mathrm{R}_{\mathrm{mt}}-\mathrm{R}_{\mathrm{rf}, \mathrm{t}}\right)
\end{array}\right]\left[\begin{array}{c}
\beta_{1,1 \mathrm{t}} \\
\beta_{1,2 \mathrm{t}} \\
\vdots \\
\beta_{1,8 \mathrm{t}}
\end{array}\right] \\
& +\left[\begin{array}{ccccccc}
1 & 0 & \cdots & 0 & \mathrm{SMB}_{\mathrm{t}} & \cdots & \left(\mathrm{U}^{2} \mathrm{RD}_{1 \mathrm{t}}\right. \\
0 & 1 & & 0 & \mathrm{SMB}_{\mathrm{t}} & & (\mathrm{U}) \mathrm{RD}_{2 \mathrm{t}} \\
\vdots & & \ddots & & \vdots & \ddots & \vdots \\
0 & \cdots & 0 & 1 & \mathrm{SMB}_{\mathrm{t}} & \cdots & \left(\mathrm{U}^{2} \mathrm{RD}_{8 \mathrm{t}}\right.
\end{array}\right]\left[\begin{array}{c}
\beta_{0,1} \\
\beta_{0,2} \\
\vdots \\
\beta_{0,8} \\
\beta_{2} \\
\vdots \\
\gamma_{7}
\end{array}\right]+\left[\begin{array}{c}
\varepsilon_{1 \mathrm{t}} \\
\varepsilon_{2 \mathrm{t}} \\
\vdots \\
\varepsilon_{8 \mathrm{t}}
\end{array}\right]
\end{aligned}
$$

and the transition equations

$$
\begin{aligned}
& {\left[\begin{array}{c}
\beta_{1,1 \mathrm{t}} \\
\beta_{1,2 \mathrm{t}} \\
\vdots \\
\beta_{1,8 \mathrm{t}}
\end{array}\right]=\left[\begin{array}{c}
\beta_{1,1 \mathrm{t}-1} \\
\beta_{1,2 \mathrm{t}-1} \\
\vdots \\
\beta_{1,8 \mathrm{t}-1}
\end{array}\right]} \\
& +\left[\begin{array}{cccc}
\text { DTCAS }_{1 \mathrm{t}} & (\mathrm{U}) \mathrm{DTCA}_{1 \mathrm{t}} & \cdots & (\mathrm{U}) \mathrm{RD}_{1 \mathrm{t}} \\
\text { DTCAS }_{2 \mathrm{t}} & \left(\mathrm{U}^{2} \mathrm{DTCA}_{2 \mathrm{t}}\right. & & (\mathrm{U}) \mathrm{RD}_{2 \mathrm{t}} \\
\vdots & \vdots & \ddots & \vdots \\
\text { DTCAS }_{8 \mathrm{t}} & (\mathrm{U}) \mathrm{DTCA}_{8 \mathrm{t}} & \cdots & (\mathrm{U}) \mathrm{RD}_{8 \mathrm{t}}
\end{array}\right]\left[\begin{array}{c}
\varphi_{1} \\
\varphi_{2} \\
\vdots \\
\varphi_{6}
\end{array}\right] \\
& +\left[\begin{array}{c}
\eta_{1 \mathrm{t}} \\
\eta_{2 \mathrm{t}} \\
\vdots \\
\eta_{8 \mathrm{t}}
\end{array}\right]
\end{aligned}
$$

where $\varepsilon_{\mathrm{it}} \sim \mathrm{N}\left(0, \sigma_{\varepsilon_{\mathrm{it}}}^{2}\right)$, the correlation between $\varepsilon_{\mathrm{it}}$ and $\varepsilon_{\mathrm{jt}}$ is equal to $\rho_{\mathrm{ij}}$, and $\eta_{\mathrm{it}} \sim \mathrm{N}\left(0, \sigma_{\eta}^{2}\right)$.

Next, we apply standard Kalman filter routines and use a numerical optimization method for the log-likelihood function to obtain the optimal parameter vector $\theta$ (for technical details, see Durbin and Koopman 2001). The parameter vector $\theta$ contains $\beta_{0 i}$; the initial values for $\beta_{1 \mathrm{it}}$; the other $\beta$ parameters; all $\gamma, \varphi$, and $\kappa$ parameters; the error variance $\sigma_{\eta}^{2}$; and correlation coefficients $\rho$. When possible, we use regression coefficients as starting values for the parameters and apply different starting values for the other parameters, where all sets of starting values converge to the same solution. We obtain the parameter standard errors from the information matrix evaluated at estimated values (Naik and Raman 2003). We use the smoothed coefficients for $\beta_{1 i t}$, which contain information from all periods. Finally, we perform standard diagnostic checks on the standardized one- step forecast errors. We test the errors for nonnormality, serial correlation, and nonconstant variance over time (here we test for autoregressive conditional heteroskedasticity).

\section{Data}

Our monthly data for 1993-2000 are for the eight largest U.S.-based drug manufacturers: Abbott, Bristol-Myers Squibb (BMS), Johnson \& Johnson (J\&J), Eli Lilly (Lilly), Merck, Pfizer, Schering-Plough (Schering), and Wyeth. ${ }^{5}$ For these firms, we have data about all prescription drugs with 2000 annual sales of $\$ 25$ million or more. We did not include GlaxoSmithKline because it likely experienced important merger and acquisition influences, and we excluded Procter \& Gamble because of the firm's diverse nature. Table 2 lists the definition of the variables and the data sources used.

We obtained data from various sources, such as Datastream, COMPUSTAT, Kenneth French's Web site, ScottLevin, and PERQ/HCI. ${ }^{6}$ With regard to stock returns, we used the total return index, which assumes that dividends are reinvested to buy additional units of equity. We transformed the quarterly profit data to monthly data using revenue-based weights; to assign the quarterly R\&D expenditures to months, we evenly distributed the expenditures over the quarter.

To measure unanticipated changes in DTCA, we followed Aaker and Jacobson (1994) and Srinivasan and colleagues (2009) and took the residuals of a first-order autoregressive model. Because we could observe seasonality, we added monthly dummies to account for seasonality effects. However, unlike the two previously mentioned studies, we did not pool the models for the unanticipated changes over the different firms. Intuitively, this makes sense because it might be assumed that investors have firm-specific expectations. This assertion is confirmed in our subsequent empirical results. With regard to $\mathrm{H}_{2}$, we tested whether the effect of DTCA on stock returns is strongest in the first six months after the regulation relaxation. Chemmanur and Yan (2009) consider a one-year period for a large number of firms. However, these firms likely did not increase their advertising budgets as abruptly and quickly as pharmaceutical firms. In addition, Fehle, Tsyplakov, and Zdorovtsov (2005) show that airing television commercials during Super Bowl broadcasts may increase a firm's stock price, confirming that individual investors have attention-driven buying strategies (Barber and Odean 2008). Therefore, compared with Chemmanur and Yan (2009), we assumed a more rapid effect on the visibility of drug manufacturers to individual investors.

For the advertising stock, DTCAS, we used Nerlove and Arrow's (1962) specification, with a square root to capture diminishing returns and a carryover parameter of .75 from Narayanan, Desiraju, and Chintagunta (2004). That is, DTCAS $_{\text {it }}=.75$ DTCAS $_{\text {it }-1}+\sqrt{\text { DTCA }_{\text {it }}}$. For the purposes of scaling, we divided the stock variables by 1000 .

5This is based on total revenues in December 2000 across all products in our database.

${ }^{6}$ For Kenneth French's Web site, see http://mba.tuck.dartmouth. edu/pages/faculty/ken.french. 
TABLE 2

Variable Definitions and Sources

\begin{tabular}{|c|c|c|}
\hline Variable & Definition & Source \\
\hline $\mathrm{R}$ & Company return, derived from the total return index & Datastream \\
\hline $\mathrm{R}_{\mathrm{m}}$ & Market return & Kenneth French's Web site \\
\hline $\mathrm{R}_{\mathrm{rf}}$ & Return on a risk-free investment & Kenneth French's Web site \\
\hline SMB & $\begin{array}{l}\text { Small-minus-big factor: return difference between portfolios } \\
\text { of small and large firms }\end{array}$ & Kenneth French's Web site \\
\hline HML & $\begin{array}{l}\text { High-minus-low factor: return difference between portfolios } \\
\text { of high and low book-to-market equity firms }\end{array}$ & Kenneth French's Web site \\
\hline UMD & $\begin{array}{l}\text { Up-minus-down factor: return difference between portfolios } \\
\text { of firms with high and low prior returns }\end{array}$ & Kenneth French's Web site \\
\hline DTCA & Direct-to-consumer advertising & Scott-Levin \\
\hline DTCAS & Direct-to-consumer advertising stock & Scott-Levin \\
\hline (U)DTCA & (Unexpected changes in) DTCA & Scott-Levin \\
\hline (U)DTP & (Unexpected changes in) DTP & $\begin{array}{l}\text { Scott-Levin, journal advertising } \\
\text { from PERQ/HCl }\end{array}$ \\
\hline (U)REV & (Unexpected changes in) revenues & Scott-Levin \\
\hline (U)PROFIT & $\begin{array}{l}\text { (Unexpected changes in) profits (quarterly profit figures are } \\
\text { distributed over months using revenue-based weights) }\end{array}$ & COMPUSTAT \\
\hline (U)RD & $\begin{array}{c}\text { (Unexpected changes in) R\&D expenditures(quarterly } \\
\text { R\&D expenditures are evenly distributed over the } \\
\text { quarters' months) }\end{array}$ & COMPUSTAT \\
\hline
\end{tabular}

Notes: We omit the firm and time indexes.

\section{Empirical Results}

\section{Descriptive Statistics}

Table 3 shows summary statistics for the key variables in the study, namely, stock returns and DTCA and DTP expenditures. For DTCA, we only took observations after the regulation relaxation into account to avoid the influence of zero values. Average monthly returns are largest for Lilly, Pfizer, and Schering, though differences from other firms are not significant. Lilly spends the least amount on DTCA and DTP; in contrast, Pfizer and Schering are the largest investors in DTCA, and Pfizer also spends the most on DTP.

Table 4 provides the correlations and variance inflation factors between our model variables. The variance inflation factors are no larger than 2.7, suggesting that multicollinearity among the variables is not a concern.

\section{Main Results}

We simultaneously estimated the equations in our dynamic four-factor model (Equations 2a-2d) using data from eight pharmaceutical firms. ${ }^{7}$ On average, across firms, our model explains approximately $28.6 \%$ of the temporal variation in

\footnotetext{
${ }^{7}$ We verified whether the different DTCAS, (U)DTCA, and (U)DTP effects could be disentangled by examining the parameter correlation matrix and found that all cross-correlations are sufficiently low. We also estimated a system of equations with each firm's DTCA expenditures as endogenous variable and obtained similar substantive results. When we tested the standardized onestep forecast errors for normality, serial correlation, and autoregressive conditional heteroskedasticity, we found that they met all standard assumptions. The auxiliary residuals (Durbin and Koopman 2001) indicated two clear outliers, which we controlled for using dummy variables.
}

TABLE 3

Summary Statistics for Key Variables

\begin{tabular}{|c|c|c|c|c|c|c|}
\hline \multirow[b]{2}{*}{ Variable } & \multicolumn{2}{|c|}{ Stock Returns } & \multicolumn{2}{|c|}{ DTCA } & \multicolumn{2}{|c|}{ DTP } \\
\hline & M & SD & M & SD & $\mathbf{M}$ & SD \\
\hline Abbott & 1.418 & 5.581 & 2.583 & 2.853 & 15.797 & 3.442 \\
\hline BMS & 1.696 & 6.098 & 6.110 & 5.121 & 21.830 & 4.440 \\
\hline J\&J & 1.618 & 6.989 & 3.548 & 1.662 & 17.781 & 2.981 \\
\hline Lilly & 2.294 & 9.374 & 1.790 & 1.732 & 9.947 & 2.512 \\
\hline Merck & 1.757 & 8.108 & 12.927 & 8.047 & 23.915 & 9.693 \\
\hline Pfizer & 2.285 & 7.625 & 14.729 & 7.687 & 58.355 & 17.319 \\
\hline Schering & 2.284 & 8.366 & 13.616 & 10.448 & 16.507 & 6.222 \\
\hline Wyeth & 1.618 & 7.966 & 2.877 & 1.327 & 11.175 & 3.627 \\
\hline
\end{tabular}

Notes: DTCA and DTP expenditures are measured in millions of U.S. dollars. Statistics for stock returns and DTP expenditures are based on 94 observations per firm (two observations per firm are lost because of the dynamics in our model). In the case of DTCA, we focus on all time periods from August 1997, resulting in 41 observations per firm (one observation is lost because of model dynamics). 


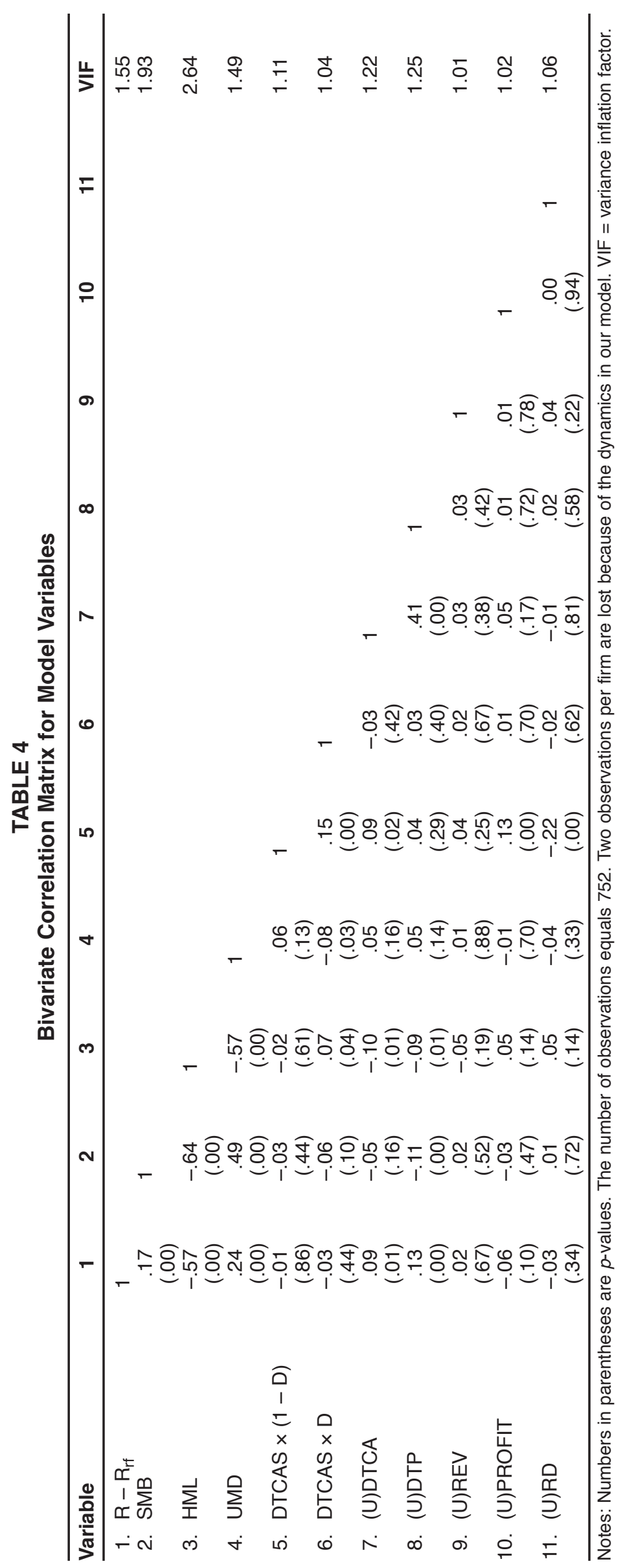


firms' stock returns. Table 5 presents the results for Equation $2 \mathrm{a}$, though without the systematic risk coefficients, which we discuss in detail together with the results for Equation 26.

From Table 5, we conclude that the constants are positive for all firms, and four of the eight constants are significant at least at $p<.05$. Therefore, these four firms seem to outperform the market systematically in our data window. With regard to $\mathrm{SMB}$ and $\mathrm{HML}$, we find significant and negative signs $(p<.01$ and $p<.05$, respectively). From the SMB coefficient, we can infer that the (typically large) pharmaceutical firms' stock returns show more correspondence with those of large firms. The negative sign of the HML variable indicates that the stock returns move together with low book-to-market equity firms. The momentum factor (UMD) is insignificant and in line with Fama and French's (1996) question about whether the momentum effect is real and their call for more empirical verification of momentum (see also Srinivasan and Hanssens 2009). We cannot directly confirm $\mathrm{H}_{1}$, because we do not find a significant effect of DTCA on stock returns for unexpected changes or the stock variable. In the months directly following the regulation relaxation, DTCA had a significantly stronger positive effect, in support of $\mathrm{H}_{2}$. Not only is the effect in this time window stronger than in other months, but DTCA also significantly increases stock returns $(p<$ .05), providing partial support for $\mathrm{H}_{1}$. These results are in line with Chemmanur and Yan (2009), who find that advertising can help attract investors' attention but that the effect may diminish in the long run because of advertising wearout or possibly saturation. The significant $(p<.05)$ and positive value for the coefficient of unexpected changes in DTP on stock returns conflicts with $\mathrm{H}_{3}$. This implies that investors do observe and value higher-than-expected DTP expenditures. Therefore, it is plausible that large investors rely more on data from companies such as IMS to track

TABLE 5

Estimation Results for Returns

\begin{tabular}{lcl}
\hline & Parameter Value & SD \\
\hline Constant Abbott & $1.015^{\star \star}$ & .516 \\
Constant BMS & $.908^{\star}$ & .534 \\
Constant J\&J & $1.131^{\star}$ & .591 \\
Constant Lilly & $2.058^{\star \star}$ & .889 \\
Constant Merck & $1.256^{\star}$ & .702 \\
Constant Pfizer & $1.754^{\star \star *}$ & .675 \\
Constant Schering & $1.492^{\star \star}$ & .718 \\
Constant Wyeth & .973 & .654 \\
SMB & $-.673^{\star \star *}$ & .148 \\
HML & $-.429^{\star \star}$ & .195 \\
UMD & -.031 & .116 \\
DTCAS $\times(1-D)$ & -.049 & .064 \\
DTCAS $\times$ D & $.323^{\star *}$ & .145 \\
(U)DTCA & .024 & .072 \\
(U)DTP & $.139^{\star *}$ & .065 \\
(U)REV & $.033^{*}$ & .019 \\
(U)PROFIT & .001 & .003 \\
(U)RD & -.003 & .021 \\
\hline
\end{tabular}

${ }^{{ }^{*} p<.1 .}$

${ }^{\star *} p<.05$.

${ }^{* * \star} p<.01$.
DTP expenditures than we concluded from our discussions with these data providers.

We provide the time-varying systematic and idiosyncratic risk measures in Figures 2 and 3, respectively. For all firms, systematic risk is far lower at the end of the second regime than it is in the first regime. In most cases, systematic risk even falls below 0 . This finding suggests that fluctuations in the returns of these firms move contrary to fluctuations in market returns. Figure 3 displays an opposite pattern: Idiosyncratic risk increases over time for all firms. The fall and rise of systematic and idiosyncratic risk, respectively, are most severe after DTCA regulations were relaxed.

Table 6 presents the parameter estimates and standard deviations for Equation $2 \mathrm{~b}$. The initial values of systematic risk are lower than 1 for six of the eight firms. Systematic risk lower than 1 indicates that the stock's return goes up

FIGURE 2

Systematic Risk over Time

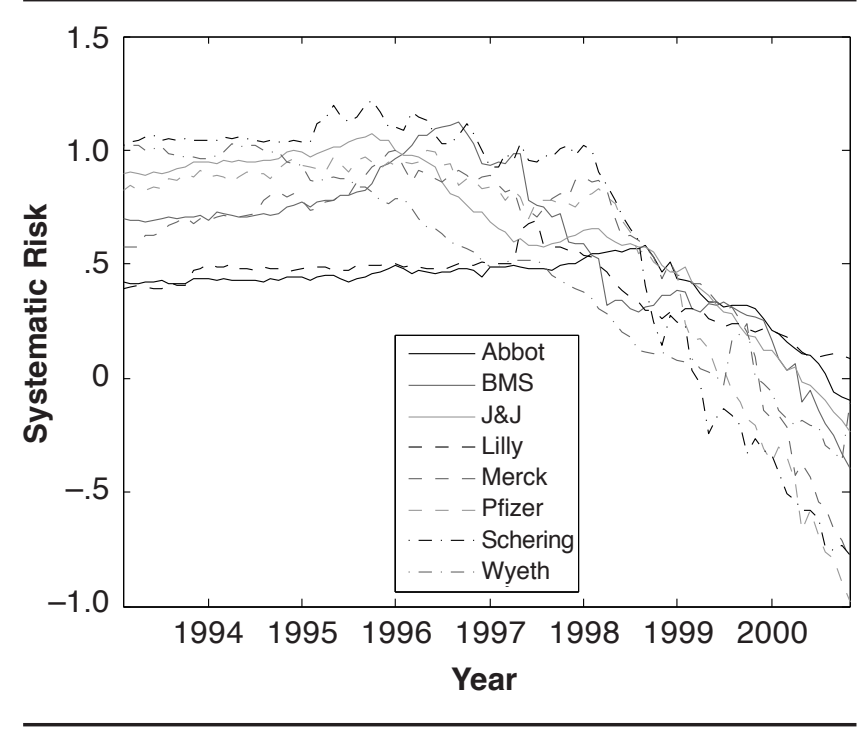

FIGURE 3
Idiosyncratic Risk over Time

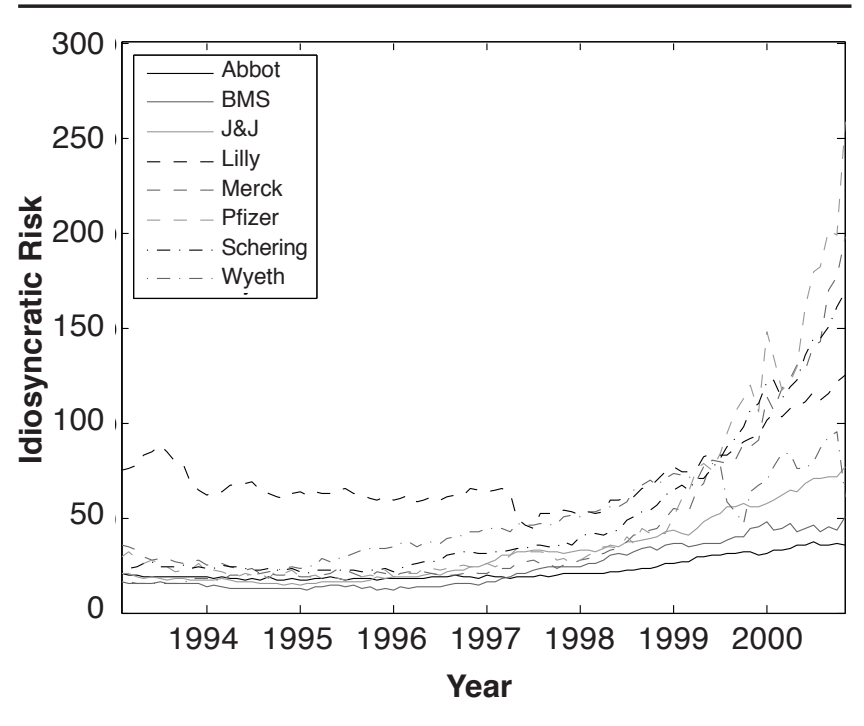


TABLE 6

Estimation Results for Systematic Risk

\begin{tabular}{lcc}
\hline & $\begin{array}{c}\text { Parameter } \\
\text { Value }\end{array}$ & SD \\
\hline Initial systematic risk Abbott & $.419^{\star \star}$ & .156 \\
Initial systematic risk BMS & $.698^{\star *}$ & .207 \\
Initial systematic risk J\&J & $.897^{\star \star}$ & .208 \\
Initial systematic risk Lilly & .394 & .270 \\
Initial systematic risk Merck & .573 & .489 \\
Initial systematic risk Pfizer & $.826^{\star \star}$ & .319 \\
Initial systematic risk Schering & $1.025^{\star *}$ & .283 \\
Initial systematic risk Wyeth & $1.013^{\star \star}$ & .293 \\
DTCAS & $-.003^{\star *}$ & .001 \\
(U)DTCA & $-.011^{*}$ & .006 \\
(U)DTP & .003 & .008 \\
(U)REV & -.001 & .002 \\
(U)PROFIT & .000 & .000 \\
(U)RD & -.001 & .002 \\
Variance error term & .001 & $.001-.001$ \\
\hline${ }^{*} p<.05$. & & \\
${ }^{* \star} p<.01$. & & \\
Notes: For the error variance, we give & $95 \%$ confidence intervals
\end{tabular}
instead of a standard deviation.

(down) to a lesser extent than the market when it goes up (down). Furthermore, we conclude that the DTCA stock and the unexpected changes in DTCA have a significant $(p<$ .01 and $p<.05$, respectively) and negative effect on systematic risk, in support of $\mathrm{H}_{4}$. We also find support for $\mathrm{H}_{5}$ because there are no changes in systematic risk due to unanticipated changes in DTP expenditures.

The parameter estimates for Equation $2 \mathrm{c}-2 \mathrm{~d}$ in Table 7 reveal a highly significant $(p<.01)$ and positive estimate for the stock of DTCA, in support of the hypothesized effect of DTCA on idiosyncratic risk $\left(\mathrm{H}_{6}\right)$. In contrast with $\mathrm{H}_{7}$, we find that unexpected changes in DTP expenditures tend to have a significant and positive effect on idiosyncratic risk $(p<.1)$, indicating that unanticipated rises in DTP expenditures lead to more uncertainty about the firm's stock price. We further note that the values of the scaling
TABLE 7 Estimation Results for Idiosyncratic Risk

\begin{tabular}{|c|c|c|c|}
\hline & $\begin{array}{c}\text { Parameter } \\
\text { Value }\end{array}$ & \multicolumn{2}{|c|}{ SD } \\
\hline TCAS & $.003^{\star \star}$ & \multicolumn{2}{|c|}{.000} \\
\hline $\mathrm{CA}$ & -.00 & \multicolumn{2}{|c|}{.006} \\
\hline & $.016^{\star}$ & \multicolumn{2}{|c|}{.008} \\
\hline EV & -.003 & \multicolumn{2}{|c|}{.002} \\
\hline U)PROFIT & .000 & \multicolumn{2}{|c|}{.000} \\
\hline (U)RD & .001 & \multicolumn{2}{|c|}{.001} \\
\hline Scaling parameter Abbott & 20.304 & 14.947 & 27.580 \\
\hline Scaling parameter BMS & 15.602 & 10.757 & 22.628 \\
\hline Scaling parameter J\&J & 20.885 & 14.727 & 29.619 \\
\hline Scaling parameter Lilly & 77.264 & 52.398 & 113.929 \\
\hline Scaling parameter Merck & 35.558 & 18.483 & 68.408 \\
\hline arameter Pfizer & 29.621 & 18.894 & 46.436 \\
\hline r Schering & 21.550 & 14.785 & 31.411 \\
\hline Scaling parameter Wyeth & 18.081 & 11.178 & 29.248 \\
\hline \multicolumn{4}{|c|}{$\begin{array}{l}{ }^{*} p<.1 . \\
{ }^{\star \star} p<.01 \text {. } \\
\text { Notes: For the scaling parameters, we give } 95 \% \text { confidence inter- } \\
\text { vals instead of a standard deviation. We transform these } \\
\text { parameters in the estimation process to ensure that they } \\
\text { meet the requirement of being strictly positive. The transfor- } \\
\text { mation also explains the asymmetric confidence intervals. }\end{array}$} \\
\hline
\end{tabular}

parameters for idiosyncratic risk greatly vary across firms, with a particularly high value for Lilly.

Our empirical findings support our DTCA-related hypotheses. However, the hypotheses regarding the effects of DTP expenditures on returns and idiosyncratic risk $-\mathrm{H}_{3}$ and $\mathrm{H}_{7}$, respectively-receive no support, though it must be noted that the effect on idiosyncratic risk is significant only at the $10 \%$ level. The results indicate that investors do observe physician-directed efforts and that unanticipated shocks in these efforts simultaneously increase stock returns and raise idiosyncratic risk. We summarize and compare our outcomes with those of McAlister, Srinivasan, and Kim (2007) and Joshi and Hanssens (2010) in Table 8; we confirm McAlister, Srinivasan, and Kim's (2007) findings about the effects of DTCA on systematic risk, and we

TABLE 8

Overview of Empirical Support for Conceptual Framework

\begin{tabular}{|c|c|c|c|}
\hline \multirow[b]{2}{*}{ Hypotheses } & \multicolumn{3}{|c|}{ Supported? } \\
\hline & $\begin{array}{l}\text { McAlister, Srinivasan, } \\
\text { and Kim (2007) }\end{array}$ & $\begin{array}{c}\text { Joshi and } \\
\text { Hanssens (2010) }\end{array}$ & This Study \\
\hline \multicolumn{4}{|l|}{ Stock Returns } \\
\hline $\mathrm{H}_{1}$ : DTCA increases stock returns. & - & Yes & Partial \\
\hline $\begin{array}{l}\mathrm{H}_{2}: \text { The effect of DTCA on stock returns is } \\
\text { strongest directly after the regulation } \\
\text { relaxation. }\end{array}$ & - & - & Yes \\
\hline $\mathrm{H}_{3}$ : DTP has no effect on stock returns. & - & - & No \\
\hline \multicolumn{4}{|l|}{ Systematic Risk } \\
\hline $\mathrm{H}_{4}$ : DTCA lowers systematic risk. & Yes & - & Yes \\
\hline $\mathrm{H}_{5}$ : DTP has no effect on systematic risk. & - & - & Yes \\
\hline \multicolumn{4}{|l|}{ Idiosyncratic Risk } \\
\hline $\mathrm{H}_{6}$ : DTCA increases idiosyncratic risk. & - & - & Yes \\
\hline $\mathrm{H}_{7}$ : DTP has no effect on idiosyncratic risk. & - & - & No \\
\hline
\end{tabular}

Notes: "-"denotes that the effect is not investigated. 
find partial support for the effect on returns, as Joshi and Hanssens's (2010) study indicates.

\section{Robustness Checks and Relevance of the Effects}

In our empirical analysis, we performed several robustness checks. First, we tested whether a higher-order model to determine the unanticipated changes leads to a better fit of the full model (Equations $2 \mathrm{a}-2 \mathrm{~d}$ ). Both the $\mathrm{BIC}$ and $\mathrm{AIC}_{\mathrm{c}}$ indicate that the model fit does not improve when we increase the number of lags. From a substantive point of view, the results are robust, apart from $\mathrm{H}_{7}$, which we cannot reject; in other words, the effect of (U)DTP on idiosyncratic risk is no longer significant when we assume a lag length exceeding three. Second, we also tested whether our results are robust to including year dummies in the unanticipated changes equations (Aaker and Jacobson 1994). Again, we found that all our conclusions hold except for the effect of (U)DTP on idiosyncratic risk, which is not significant. We expected a stronger effect in the months following the regulation relaxation. To test the sensitivity of our results to the assumption of a time window of six months, we estimated our model assuming windows of three to nine months. We obtained similar substantive results in all cases: The findings in Table 8 do not change. Finally, to test the sensitivity to the assumption of a DTCA stock carryover parameter of .75 , we estimated the model assuming carryover parameter values in the range of .6 and .9 , with a step size of .05 and again found the results, including those reported in Table 8, to be robust.

To explicate the relevance of our results, we first assessed the changes in the percentage of variance explained by estimating our model without the DTCA variables and then without the DTP variables. The model without the DTCA variables has an R-square of .236, or a decline of $17.4 \%$ in explanatory power compared with the full model (Equations 2a-2d). Therefore, we conclude that DTCA plays an important role in explaining firm stock returns. However, the explanatory power of the model without the DTP components declines only marginally; that is, with an R-square of .280 , the percentage of variance explained decreases by only $2.3 \%$. Although it is significant, DTP expenditures are far less important for explaining stock returns than DTCA. In addition, we assessed the contribution of each of the hypothesized effects to the model fit. ${ }^{8}$ Comparison of these fit statistics with those for the full model indicate that the effects of DTCA on systematic and idiosyncratic risk, as related to $\mathrm{H}_{4}$ and $\mathrm{H}_{6}$, respectively, contribute most to the model fit.

\section{Managerial Implications}

Our study offers several managerial implications. Managers who evaluate marketing expenditures should consider the effects of marketing on all stakeholders, not just consumers,

${ }^{8}$ We estimated models leaving out the effects described in the specific hypothesis and determined $\mathrm{BIC}$ and $\mathrm{AIC}_{\mathrm{c}}$ statistics. We thank an anonymous reviewer for suggesting this analysis. A table with $\mathrm{BIC}$ and $\mathrm{AIC}_{\mathrm{c}}$ values is available on request from the first author. which should significantly influence the size and allocation of the marketing budget. We illustrate this through a scenario analysis that indicates the consequences of a change in DTCA expenditures on stock returns and risk. Existing research indicates that at least some expenditures on DTCA may be better allocated elsewhere (e.g., Law, Majumdar, and Soumerai 2008).

We calculated the stock return and risk impact when there was a $20 \%$ decrease in DTCA expenditures for all periods from August 1997, the month of the regulation relaxation, to December 2000. This decrease affected both the advertising stock variable and the unexpected changes in advertising variable. We retained all other variables at their original levels and took both significant and insignificant variables into account. We assessed the short- and long-term financial consequences of a decrease in DTCA. These are defined, respectively, as the first six months following the relaxation of the regulation and all periods from August 1997 to December 2000. We determined the percentage change in cumulative returns over the time window considered, and for systematic and idiosyncratic risk, we evaluated the change and percentage change, respectively, in the final period of the considered time window compared with the original situation.

Our results show that, on average, the decrease in DTCA expenditures decreases cumulative returns by $5.3 \%$ and increases systematic risk by only .01 in the short run. Across firms, idiosyncratic risk is $.3 \%$ lower than in the original situation. However, this does not affect investors who hold a well-diversified portfolio. In the long run, the negative effect on cumulative returns dissipates because of the insignificant but negative effect of DTCA on returns (DTCAS parameter $=-.049$ ). However, the effect on systematic risk is more severe, with an average increase of .14. Idiosyncratic risk drops $10.5 \%$. Our results indicate that a reduction in DTCA expenditures predominantly affects returns in the short run, whereas the effect on systematic risk is more pronounced in the long run.

A possible explanation for this finding is that in the short run, DTCA enhances the firms' prospects as well as the salience for individual investors. In turn, this increases the demand for the firms' stocks. In the long run, more stable cash flows and a more diversified investor base (i.e., less coordinated buying and selling decisions) lead to lower systematic risk. A consideration of sales effects alone likely would lead to a decrease in DTCA expenditures (see Kremer et al. 2008). Given the strong DTCA effects on shareholder value, this decrease would be detrimental from a shareholder's point of view. Thus, DTCA and DTP serve different goals, and both components should be integral parts of an overall marketing communication strategy.

\section{Conclusions, Limitations, and Further Research}

We study the effects of DTCA and DTP expenditures for pharmaceuticals. Relying on Kalman filtering, we demonstrate that marketing expenditures with limited sales effects can influence the three components of shareholder value: stock returns, systematic risk, and idiosyncratic risk. 
We demonstrate that DTCA not only increases stock returns but also decreases systematic risk. These outcomes are comparable to Fornell and colleagues' (2006) findings regarding the relationships among customer satisfaction, risk, and return. Moreover, we found that DTCA increases idiosyncratic risk, though we note that this increase does not affect investors who maintain a well-diversified portfolio. The increase in idiosyncratic risk likely occurs because investors perceive DTCA as a risky investment. It is also plausible that investors become more involved with the company, which would lead to a stronger response to companyspecific news. Whereas previous research has focused primarily on the levels of returns, we uncover important relationships among strategic marketing variables, including DTCA, DTP, levels of stock return, and the two components of risk. Thus, our study highlights the strategic importance of DTCA, which increases returns and reduces systematic risk, thus enhancing long-term shareholder wealth. The impact of advertising on stock performance is indicative of market inefficiency and enables firms to beat competition in offering superior shareholder value. ${ }^{9}$ In turn, this effect helps shape the perspective of finance managers who are concerned about the uncertain impact of DTCA, given its moderate sales impact. A key managerial implication is that firms should strike a balance in their DTCA expenditures to optimize the net benefits from a shareholder perspective.

Our study has several limitations. First, we rely on aggregate data. More accurate results might be obtained by surveying investors to determine how marketing activities (e.g., DTCA, DTP) influence their behavior. Second, we use autoregressive models to determine unanticipated changes in the variables. A fruitful research avenue would be to assess how investors form expectations and how these expectations can be captured when using aggregate data.

${ }^{9}$ We thank an anonymous reviewer for bringing this to our attention.
Third, we do not take into account the rise of Web trading, which overlaps with our data window. For example, Schwab's Web trading service went live in 1996 (Charles Schwab Corporation 2009). Easy access to the stock market for individual investors may have reinforced DTCA effects; that is, a firm's increased salience for individual investors due to DTCA better translates into shareholder value because of easy access to the stock market.

We identify several additional directions for further research. First, an extension of our findings to other industries and in both business-to-business and business-to-consumer contexts would reinforce our conclusions. To the extent that investors directly observe advertising, our approach is suitable in both contexts. Because investors might directly observe promotional efforts in a business-to-consumer context and their effects might only become clear from the company's books in a business-to-business context, it is important to determine how the stock market effects differ across contexts. Second, additional research should distinguish between the impact of DTCA for firms that introduce many new products and those that mainly use DTCA to support existing brands. Third, researchers could attempt to disentangle the effects of DTCA for ethical drugs with large versus small market potential, incorporating the company's product portfolio composition into their analyses. Fourth, insights into the relationship between marketing investments and their ultimate effect on shareholder value might be improved by including intermediate customer mind-set metrics, such as brand awareness and brand liking (Srinivasan, Vanhuele, and Pauwels 2010), and marketing asset metrics, such as customer equity and brand equity. Finally, a challenge for further research would be to develop a structural model of a firm's marketing actions and investor behavior. In summary, our work contributes to ongoing efforts, of practitioners and academics alike, by underscoring the importance of assessing the contribution of the marketing actions in light of their impact on the firm's ultimate goal of maximizing shareholder wealth.

\section{REFERENCES}

Aaker, David A. and Robert Jacobson (1994), "The Financial Information Content of Perceived Quality," Journal of Marketing Research, 31 (May), 191-201.

_ and (2001), "The Value Relevance of Brand Attitude in High-Technology Markets," Journal of Marketing Research, 38 (November), 485-93.

Amaldoss, Wilfred and Chuan He (2009), "Direct-to-Consumer Advertising of Prescription Drugs: A Strategic Analysis," Marketing Science, 28 (3), 472-87.

Ataman, Berk, Carl F. Mela, and Harald J. van Heerde (2008), "Building Brands," Marketing Science, 27 (6), 1036-1054.

Bansal, Pratima and Iain Clelland (2004), "Talking Trash: Legitimacy, Impression Management, and Unsystematic Risk in the Context of the Natural Environment," Academy of Management Journal, 47 (1), 93-103.

Barber, Brad M. and Terrance Odean (2008), "All That Glitters: The Effect of Attention and News on the Buying Behavior of Individual and Institutional Investors," Review of Financial Studies, 21 (2), 785-818.
Barth, Mary E., Michael B. Clement, George Foster, and Ron Kasznik (1998), "Brand Values and Capital Market Valuation," Review of Accounting Studies, 3 (1-2), 41-68.

Berndt, Ernst R., Linda Bui, David R. Reiley, and Glen L. Urban (1995), "Information, Marketing, and Pricing in the U.S. Antiulcer Drug Market," American Economic Review, 85 (2), 100-105.

Braun, Philip A., Daniel B. Nelson, and Alain M. Sunier (1995), "Good News, Bad News, Volatility, and Betas," Journal of Finance, 50 (5), 1575-603.

Brealy, Richard A., Stewart C. Myers, and Alan J. Marcus (2001), Fundamentals of Corporate Finance. New York: Irwin/ McGraw-Hill.

Cai, Zongwu (2007), "Trending Time-Varying Coefficient Time Series Models with Serially Correlated Errors," Journal of Econometrics, 136 (1), 163-88.

Campbell, John Y., Martin Lettau, Burton G. Malkiel, and Yexiao Xu (2001), "Have Individual Stocks Become More Volatile? An Empirical Exploration of Idiosyncratic Risk," Journal of Finance, 56 (1), 1-43. 
Carhart, Mark M. (1997), "On Persistence in Mutual Fund Performance," Journal of Finance, 52 (1), 57-82.

Charles Schwab Corporation (2009), "About Schwab: History," (accessed September 22, 2010), [available at http://www. aboutschwab.com/about/history/index.html].

Chemmanur, Thomas and An Yan (2009), "Advertising, Attention, and Stock Returns," working paper, Carroll School of Management, Boston College.

Durbin, James and Siem J. Koopman (2001), Time Series Analysis by State Space Methods. New York: Oxford University Press.

Erickson, Gary and Robert Jacobson (1992), "Gaining Comparative Advantage Through Discretionary Expenditures: The Returns to R\&D and Advertising," Management Science, 38 (9), 1264-79.

Fama, Eugene F. (1970), "Efficient Capital Markets: A Review of Theory and Empirical Work," Journal of Finance, 25 (2), 282-417.

— and Kenneth R. French (1996), "Multifactor Explanations of Asset Pricing Anomalies," Journal of Finance, 51 (1), 55-84.

Fehle, Frank, Sergey Tsyplakov, and Vladimir Zdorovtsov (2005), "Can Companies Influence Investor Behavior Through Advertising? Super Bowl Commercials and Stock Returns," European Financial Management, 11 (5), 625-47.

Fischer, Marc, Hyun Shin, and Dominique M. Hanssens (2009), "The Impact of Marketing Expenditures on the Volatility of Revenues and Cash Flows," working paper, Anderson School of Management, University of California, Los Angeles.

Fornell, Claes, Sunil Mithas, Forrest Morgeson, and M.S. Krishnan (2006), "Customer Satisfaction and Stock Prices: High Returns, Low Risk,” Journal of Marketing, 70 (January), 3-14.

Frieder, Laura and Avanidhar Subrahmanyam (2005), "Brand Perceptions and the Market for Common Stock," Journal of Financial and Quantitative Analysis, 40 (1), 57-85.

Ghysels, Eric (1998), "On Stable Factor Structures in the Pricing of Risk: Do Time-Varying Betas Help or Hurt?" Journal of Finance, 53 (2), 549-73.

Grullon, Gustavo, George Kanatas, and James P. Weston (2004), "Advertising, Breadth of Ownership and Liquidity," Review of Financial Studies, 17 (2), 439-61.

Iizuka, Toshiaki and Ginger Zhe Jin (2005), "The Effect of Prescription Drug Advertising on Doctor Visits," Journal of Economics and Management Strategy, 14 (3), 701-727.

IMS Health (2009), "U.S. Promotional Information: Promotional Spend by Type," (accessed March 10, 2009), [available at http:// www.imshealth.com/deployedfiles/imshealth/Global/Content/ StaticFile/Top_Line_Data/PromotionalSpendChartWebsite.pdf].

Joshi, Amit and Dominique M. Hanssens (2010), "The Direct and Indirect Effects of Advertising Spending on Firm Value," Journal of Marketing, 74 (January), 20-33.

Kremer, Sara T.M., Tammo H.A. Bijmolt, Peter S.H. Leeflang, and Jaap E. Wieringa (2008), "Generalizations on Pharmaceutical Marketing Effectiveness," International Journal of Research in Marketing, 25 (4), 234-46.

Lane, Vicki and Robert Jacobson (1995), "Stock Market Reactions to Brand Extension Announcements: The Effects of Brand Attitude and Familiarity," Journal of Marketing, 59 (January), 63-77.

Law, Michael R., Sumit R. Majumdar, and Stephen B. Soumerai (2008), "Effect of Illicit Direct to Consumer Advertising on Use of Etanercept, Mometasone, and Tegaserod in Canada: Controlled Longitudinal Study," British Medical Journal, 337:a1055.

Lou, Dong (2009), “Attracting Investor Attention Through Advertising," working paper, London School of Economics.

Luo, Xueming (2007), "Consumer Negative Voice and FirmIdiosyncratic Stock Returns," Journal of Marketing, 71 (July), $75-88$. and C.B. Bhattacharya (2009), "The Debate over Doing Good: Corporate Social Performance, Strategic Marketing Levers, and Firm-Idiosyncratic Risk," Journal of Marketing, 73 (November), 198-213.

Madden, Thomas J., Frank Fehle, and Susan Fournier (2006), "Brands Matter: An Empirical Demonstration of the Creation of Shareholder Value Through Branding," Journal of the Academy of Marketing Science, 34 (2), 224-35.

Manchanda, Puneet, Dick R. Wittink, Andrew Ching, Paris Cleanthous, Min Ding, Xiaojing J. Dong, et al. (2005), "Understanding Firm, Physician and Consumer Choice Behavior in the Pharmaceutical Industry," Marketing Letters, 16 (3-4), 293 308.

McAlister, Leigh, Raji Srinivasan, and Min-Chung Kim (2007), "Advertising, Research and Development, and Systematic Risk of the Firm," Journal of Marketing, 71 (January), 35-48.

Mizik, Natalie and Robert Jacobson (2008), "Financial Value Impact of Perceptual Brand Attributes," Journal of Marketing Research, 45 (February), 15-32.

Naik, Prasad A., Murali K. Mantrala, and Alan G. Sawyer (1998), "Planning Media Schedules in the Presence of Dynamic Advertising Quality," Marketing Science, 17 (3), 214-35.

and Kalyan Raman (2003), "Understanding the Impact of Synergy in Multimedia Communications," Journal of Marketing Research, 40 (November), 375-88.

Narayanan, Sridhar, Ramarao Desiraju, and Pradeep K. Chintagunta (2004), "Return on Investment Implications for Pharmaceutical Promotional Expenditures: The Role of MarketingMix Interactions," Journal of Marketing, 68 (October), 90-105.

Nerlove, Marc and Kenneth J. Arrow (1962), "Optimal Advertising Policy Under Dynamic Conditions,” Economica, 29 (114), 129-42.

Osinga, Ernst C., Peter S.H. Leeflang, and Jaap E. Wieringa (2010), "Early Marketing Matters: A Time-Varying Parameter Approach to Persistence Modeling," Journal of Marketing Research, 47 (February), 173-85.

Parnes, Bennett, Peter C. Smith, Christine Gilroy, Javan Quintela, Caroline, B. Emsermann, L. Miriam Dickinson, and John M. Westfall (2009), "Lack of Impact of Direct-to-Consumer Advertising on the Physician-Patient Encounter in Primary Care: A SNOCAP Report," Annals of Family Medicine, 7 (1), 41-46.

Pauwels, Koen, Jorge Silva-Risso, Shuba Srinivasan, and Dominique M. Hanssens (2004), "New Products, Sales Promotions, and Firm Value: The Case of the Automobile Industry," Journal of Marketing, 68 (October), 142-56.

Rao, Vithala R., Manoj K. Agarwal, and Denise Dahlhoff (2004), "How Is Manifest Branding Strategy Related to the Intangible Value of a Corporation?" Journal of Marketing, 68 (October), 126-41.

Rosenthal, Meredith B., Ernst R. Berndt, Julie M. Donohue, Richard G. Frank, and Arnold M. Epstein (2002), "Promotion of Prescription Drugs to Consumers," New England Journal of Medicine, 346 (7), 498-505.

Rust, Roland T., Katherine N. Lemon, and Valarie A. Zeithaml (2004), "Return on Marketing: Using Customer Equity to Focus Marketing Strategy," Journal of Marketing, 68 (January), 109-127.

Sood, Ashish and Gerard J. Tellis (2009), "Do Innovations Really Pay Off? Total Stock Market Returns to Innovation," Marketing Science, 28 (3), 442-56.

Sorescu, Alina, Venkatesh Shankar, and Tarun Kushwaha (2007), "New Product Preannouncements and Shareholder Value: Don't Make Promises You Can't Keep," Journal of Marketing Research, 44 (August), 468-89.

- and Jelena Spanjol (2008), "Innovation's Effect on Firm Value and Risk: Insights from Consumer Packaged Goods," Journal of Marketing, 72 (April), 114-32. 
Srinivasan, Shuba and Dominique M. Hanssens (2009), "Marketing and Firm Value: Metrics, Methods, Findings, and Future Directions," Journal of Marketing Research, 46 (June), 293-312.

- Koen Pauwels, Jorge M. Silva-Risso, and Dominique M. Hanssens (2009), "Product Innovations, Advertising, and Stock Returns," Journal of Marketing, 73 (January), 24-43.

- Marc Vanhuele, and Koen Pauwels (2010), "Mind-Set Metrics in Market Response Models: An Integrative Approach," Journal of Marketing Research, 47 (August), 672-84.

Srivastava, Rajendra K., Tasadduq A. Shervani, and Liam Fahey (1998), "Market-Based Assets and Shareholder Value: A Framework for Analysis," Journal of Marketing, 62 (January), $2-18$.

Stremersch, Stefan and Walter van Dyck (2009), "Marketing of the Life Sciences: A New Framework and Research Agenda for a Nascent Field," Journal of Marketing, 73 (July), 4-30.

Tellis, Gerard J. and Joseph Johnson (2007), "The Value of Quality," Marketing Science, 26 (6), 758-73.

Vakratsas, Demetrios and Tim Ambler (1999), "How Advertising Works: What Do We Really Know?" Journal of Marketing, 63 (January), 26-43.

Van Everdingen, Yvonne M., Wouter B. Aghina, and Dennis Fok (2005), "Forecasting Cross-Population Innovation Diffusion: A Bayesian Approach," International Journal of Research in Marketing, 22 (3), 293-308.
Van Heerde, Harald J., Carl F. Mela, and Puneet Manchanda (2004), "The Dynamic Effect of Innovation on Market Structure," Journal of Marketing Research, 41 (May), 166-83.

Veliyath, Rajaram and Stephen P. Ferris (1997), "Agency Influences on Risk Reduction and Operating Performance: An Empirical Investigation Among Strategic Groups," Journal of Business Research, 39 (3), 219-27.

Vogelheim, Paul, Denise D. Schoebachler, Geoffrey L. Gordon, and Craig C. Gordon (2001), "The Importance of Courting the Individual Investor," Business Horizons, 44 (1), 69-76.

Wittink, Dick R. (2002), "Analysis of ROI for Pharmaceutical Promotions," unpublished study conducted for the Association of Medical Publications, (accessed September 22, 2010), [available at http://www.rxpromori.org/arpp/index.html].

Wosinska, Marta (2005), "Direct-to-Consumer Advertising and Drug Therapy Compliance," Journal of Marketing Research, 42 (August), 323-32.

Xie, Jinhong, Michael X. Song, Marvin Sirbu, and Qiong Wang (1997), "Kalman Filter Estimation of New Product Diffusion Models," Journal of Marketing Research, 34 (August), 378-93.

$\mathrm{Xu}$, Yexiao and Burton G. Malkiel (2003), "Investigating the Behavior of Idiosyncratic Volatility," Journal of Business, 76 (4), 613-44. 